\title{
Analysis on Evolution Model of Zombie Company under the Absence of Bank Data
}

\author{
Xiangling Fu \\ School of Software \\ Engineering \\ Beijing University of Posts \\ and Telecommunications \\ fuxiangling@bupt.edu.cn
}

\author{
Jiayin Qi \\ School of Management \\ Shanghai University of \\ International Business and \\ Economics \\ qiiiayin@139.com
}

\author{
Lulian Zou \\ International School \\ Beijing University of Posts \\ and Telecommunications \\ zoululian@163.com
}

\author{
Yi Hou \\ China Huarong Asset \\ Management Co. Ltd. \\ Shanghai Pilot Free Trade \\ Zone Branch \\ yihou@chamc.com.cn
}

\begin{abstract}
In view of the fact that the data of bank loaning is difficult to be collected, this paper innovatively explores the evolution model of zombie companies by text analysis based on the researches of previous papers at home and abroad based on the financial data of zombie companies. Through the relevant researches on 27 zombies collected, the common characteristics of zombies are found out by the grounded theory. According to the relevant models of enterprise life cycle theory, the evolution model of zombie companies is drawn up, and the corresponding feedback loop of system dynamics causality in each link is further found out, so as to explore the evolutionary rules and the reasons of zombie companies, which is helpful for government to further research on zombies, and favorable for the efficient allocation of market resources and the further rapid development of social economy.
\end{abstract}

\section{Introduction}

Economist Edward. J. Kane (1987) has proposed the concept of Zombie Company, which refers to the company has been caught in a financial crisis but still survive with the help from creditors [1]. Zombie companies seriously disturb the market economic order and waste social resources. Through studying the formation and evolution of zombie companies, it is of great value and significance to find the development path of zombie companies. So far, previous research on zombie companies has focused on the banks' nonperforming loan and loss incurred from operations. Although these methods can avoid some errors, in fact, it is hard to obtain private data such as enterprise loans from National Regulatory Agency, meanwhile the production and performance of zombie enterprises in the market are not exactly the same, so they cannot be forced to shut down directly, which can only be accurately identified and classified. In the case of considerable difficulty in data acquisition, this paper studies the development and evolution process of zombie enterprises on the basis of text analysis. The evolutionary characteristics of zombie companies are summarized in this paper. It provides a theoretical reference for identifying and eliminating zombie companies in the market. The government can immediately take remedial measures based on these characteristics to prevent further deterioration of the business situation, and it is conducive to the more effective allocation of resources and the promotion of market economic development.

\section{Literature review}

\subsection{The measure to judge zombie companies}

There are two aspects to judge zombie companies, which are situations of enterprise loans and enterprise operations.

(1) From the perspective of enterprise loans:

- CHK (Caballero,2008)

Key point is enterprises receive bank subsidies. The measurement is:

$$
\frac{R_{i, t}-R_{i, t}^{*}}{B_{i, t-1}}>0
$$

- FN (Fukuda \& Nakamura, 2011)

Key point is profitability standards and credit standards. When the bank loan interest and enterprise tax have not yet been paid, the company's operating income should be higher than the calculated optimal interest rate for bank loans. In addition, about credit 
standards, there are three specific conditions under this standard, that is, the enterprise has the asset-liability ratio of more than $50 \%$ in the previous year, the enterprise continues to increase the external loan of this year, and the enterprise's earnings before interest and tax of this year are obviously lower than the optimal interest rate of the calculated bank loan. For a company, if it is already under a high level of debt but is still increasing its bank loans, it is clearly a typical zombie company that relies on bank loans to survive in the market [2].

From this perspective, the indicators are clear and easy to use, but it is difficult to obtain specific corporate credit conditions, the evaluation results are prone to errors, and there is no agreement on the measurement of corporate asset-liability ratio in the FN method and excessive borrowing law [3].

(2)From the perspective of enterprise operations:

- Actual profit law I

Measured by: Actual net profit = net profit - nonrecurring gains and losses. Non-recurring gains and losses are an indicator of the income or expenses incurred by a company in an accidental situation and have no direct link with the normal business activities of the company. If the actual net profit value is negative, the possibility that the company is a zombie enterprise is extremely high [4].

- Actual profit law II

Calculated as: Actual net profit $=$ net profit government grant - tax rebate. If the company's net profit is originally a positive value, but after deducting the income generated by the two sub-projects, it becomes a negative value, which is even more likely that the company is a zombie enterprise [5].

From this perspective, it is more objective and accurate. However, profit and loss are not the fundamental criteria for judging whether a company is good or bad. In particular, companies in the early days of startup are prone to misjudgment.

\section{2 The cause of formation for zombie companies}

Giannetti and Simonov figured out (2013) the root of zombie companies resulted from government's inappropriate assistance and market failure by changing economic environment [6]. But peek and Rosengren (2005) thought the main reason is that banks are trying to cover up bad loans. In addition, Chernobai and Yasuda (2013) argued that the government's lose control, especially the pressure of the government on employment protection, indulged the bank's misconduct [7]. Kashyap (2002) indicated that the low interest rate monetary policy is an important driving factor for zombie companies [8].

\section{Building data sets}

\subsection{Data collection}

Aimed to protecting listed enterprises, the list of zombie companies has not been published, so the only way to get data is by related news reports on the Internet. Through the integration of enterprises listed in the three news reports ${ }^{1}$, it finally gets a list of 27 zombie enterprises, as shown in Table 1.

Table 1. List of $\mathbf{2 7}$ zombie enterprises

\begin{tabular}{|c|c|}
\hline Industry & Enterprise \\
\hline Agricultural Chemicals & $\begin{array}{l}\text { YUNNAN YUNTIANHUA } \\
\text { CO.,LTD }\end{array}$ \\
\hline Real estate development & $\begin{array}{l}\text { HENAN ORIENTAL SILVER } \\
\text { STAR INVESTMENT CO.,LTD }\end{array}$ \\
\hline Electronic component & Luoyang Glass Co., Ltd. \\
\hline Food processing & $\begin{array}{l}\text { Henan Huaying Agricultural } \\
\text { Development Co., Ltd. }\end{array}$ \\
\hline Oil and gas & $\begin{array}{l}\text { SINOPEC YIZHENG CHEMICAL } \\
\text { FIBRE CO., LTD }\end{array}$ \\
\hline Ocean Shipping & $\begin{array}{l}\text { CHINA COSCO HOLDINGS CO, } \\
\text { LTD }\end{array}$ \\
\hline Basic Chemicals & YUNNANYUNWEICO.,LTD \\
\hline Building materials & $\begin{array}{l}\text { Fujian Cement Co., Ltd, Henan } \\
\text { Ancai Hi-tech Co., Ltd. }\end{array}$ \\
\hline Paper products & $\begin{array}{l}\text { Luohe Yinge Industrial Group Co., } \\
\text { Ltd, YUEYANG FOREST \& } \\
\text { PAPER CO., LTD }\end{array}$ \\
\hline New energy generation & Min Neng Group Co., Ltd. \\
\hline Industrial machinery & Zhongyuan Special Steel Co., Ltd. \\
\hline Metal & $\begin{array}{l}\text { NINGXIA ORIENT TANTALUM } \\
\text { INDUSTRY CO., LTD }\end{array}$ \\
\hline Aluminum & $\begin{array}{l}\text { ALUMINUM CORPORATION OF } \\
\text { CHINA, HENAN ZHONGFU }\end{array}$ \\
\hline \multicolumn{2}{|c|}{$\begin{array}{l}{ }^{1} \text { The three news reports are: } \\
\text { (1) } 21 \text { st Century Business Herald, " } 266 \text { A shares of zombie } \\
\text { companies have liabilities of } 1.6 \text { trillion, and receive } 2,500 \text { billion in } \\
\text { three years", } \\
\text { http://money.163.com/api/15/1119/06/B8OUKSFR00251LIE.html, } \\
2015 . \\
\text { (2) DaheNet "266 A-share zombie companies have no profit but } \\
\text { high debt and receive subsidies", } \\
\text { http://news.sohu.com/20151126/n428251892.shtml, } 2015 . \\
\text { (3) Du Yumeng, "Traditional manufacturing in } 266 \text { zombie } \\
\text { companies accounted for more than } 70 \% \text {." } \\
\text { http://stock.hexun.com/2016-02-24/182395223.html, } 2016 .\end{array}$} \\
\hline
\end{tabular}


INDUSTRY CO ,.LTD

Coal

Taiyuan Coal Gas Group Co., Ltd, ANTAI GROUP CO.,LTD,

HEILONGJIANG HEIHUA CO.,LTD

Construction machinery

CSSC OFFSHORE \& MARINE ENGINEERING(GROUP)COMPA NY, SINOMACH CHANGLIN COMPANY LIMITED, CHINA STATE SHIPBUILDING CORPRATION LIITED

Steel

SHANDONG IRON \& STEEL GROUP CO., LTD, HANGZHOU IRON \&STEEL GROUP CO., LTD, VALIN GROUP, Lingyuan Iron \& Steel Co., Ltd, Chongqing Iron \& Steel Limited by Share Ltd

As can be seen from Table 3 above, the majority of zombie enterprises are distributed in the traditional economic sectors such as steel, coal, oil, electricity, metallurgy and some overcapacity industries.

According to the list of zombie companies, using the Wind information bank, we've been able to get more information about network public opinion and announcements of companies. Because the Internet has been widely used in the last few years, the paper takes Enterprise public opinion text information of enterprises as the original data record to study zombies, which is obtained from 2009 to 2016 in the Wind ${ }^{2}$ database.

\subsection{Data processing based on grounded theory}

Grounded theory was proposed by Anselm Strauss and Barney Glaser of Columbia University, which is developed based on the real data, and focus on data and interaction, including theoretical deduction and induction. The proposed hypothesis is compared and revised repeatedly with the actual data, and the final theoretical model is constructed after the successful verification of these repeated steps [9].

Based on grounded theory, this paper analyzes the original data by combining substantive coding with theoretical coding. At the same time, in order to ensure the accuracy of data analysis results, manual labeling analysis method was used to collate and analyze the original data records. In order to ensure the accuracy and validity of the grounded theory, 27 zombie enterprises were decoded respectively.

\footnotetext{
${ }^{2}$ Wind: Chinese market's precision financial data service provider. It provides accurate, timely and complete landing data for quantitative investment and various financial business systems. It covers stocks, bonds, funds, derivatives, indices, macro industries and other financial market data.
}

3.2.1 Open coding. The main decoding process is shown in Figure 1. At first the corresponding class genus of the statement content is found from the original data record, and the corresponding class genus is named, so as to determine the specific attributes and dimensions of the class genus. And then, the phenomenon in the study is named and categorized, which means that each and paragraph in every news report will be decomposed and summarized.

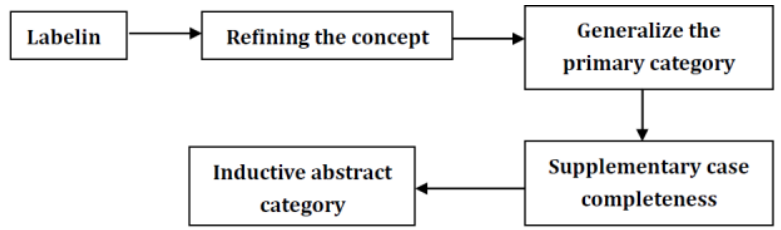

Figure 1. Decoding process

After decoding the cases of 27 zombie companies respectively, the decoding results were analyzed. It was found that some zombie enterprises' cases had increased or decreased to a certain extent. Finally, there are 12 primary categories, including funds raised, corporate adjustments, industry volatility, government subsidies, Performance loss, macro impacts, criticism penalties, and turnaround of loss, performance gains, asset restructuring, legal actions and senior management changes. After repeated induction and abstract, finally form 4 kinds of categories and a category of "concept words "consisted by enterprise capital acquisition, asset restructuring, enterprise performance impact and the influence of social environment, shown in Figure 2.

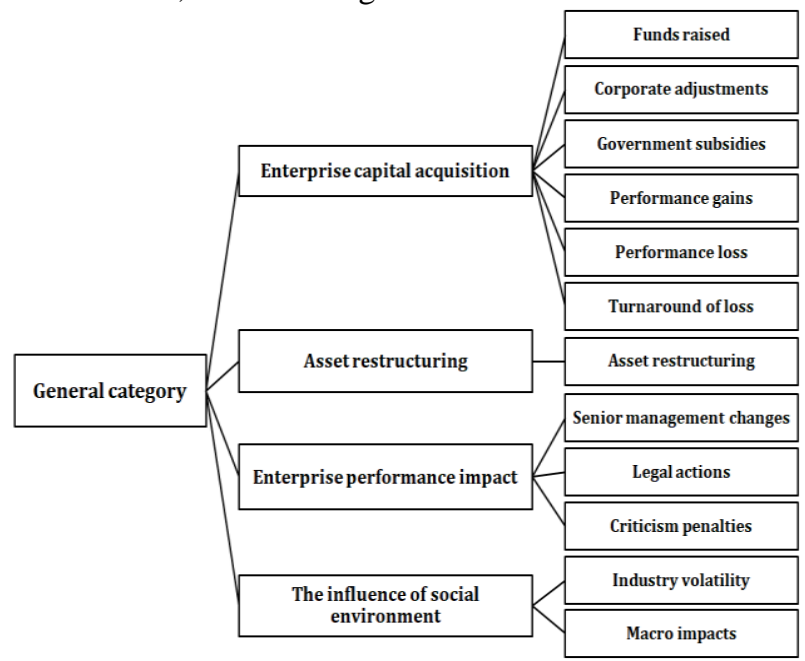

Figure 2. Impact Categories

3.2.2 Spindle decoding. This stage is the discovery and establishment of all the independent concepts involved in the previous stage, which ensures that the various parts in the original data record can be included.

This paper classifies different categories according to their mutual relations and logical order at 
the conceptual level. By classifying and abstracting the four categories obtained in the open decoding code, two main categories are obtained, namely "enterprise self-help process" and "enterprise volatility process", as shown in Table 2.

Table 2. Category relations

\begin{tabular}{ll}
\hline Spindle decoding category & Open coding category \\
\hline Enterprise self-help process & $\begin{array}{l}\text { Enterprise capital acquisition, } \\
\text { Asset restructuring }\end{array}$ \\
Enterprise volatility process & $\begin{array}{l}\text { Enterprise performance } \\
\text { impact, The influence of } \\
\text { social environment }\end{array}$ \\
\hline
\end{tabular}

"Enterprise fluctuation" means that an enterprise influences own profit when it is affected by external macroscopic environmental and industrial market, which make enterprise's operating performance fluctuate and gradually get into the row of the zombies. The "corporate self-saving process" is the kind of measures that enterprises take to make sure that they can survive in the market when they are trapped in a huge loss of their own performance. It can help them escape the risk of going private, which is the main reason that zombie enterprises can exist in the market. Table 3-6 presents a specific model of spindle decoding of the main category.

3.2.3 Selective decoding. The dominant and inclusive core genera are further explored from the genera of main concept, which can cover the majority of analysis results in a wide range of theories. After understanding the relationship among the related categories of zombie companies, the behavior phenomena and context conditions are described in the way of "story line", and a new substantial theoretical framework is further developed.

\section{Evolution Model Analysis of Zombie Company}

\subsection{Development cycle model of zombie companies}

"Enterprise life cycle theory" was proposed by the Ichak Adizes (1989), which contains the enterprise's development and growth of dynamic path, including the development, growth, maturity and decline stages. Based on the enterprise's life cycle theory, the paper focuses on the features of enterprise development stage as it enters the bureaucratic period, so as to draw a model of the cycle theory of zombie companies. The horizontal axis represents the appearance of zombies in different periods of time, and the rise and fall of the vertical axis curve represents the growth and decline of zombies' performance. Based on grounded theory process of 27 known zombie companies, the cycle diagram of the development and evolution model of 5 zombie companies are finally obtained, through combing and analyzing the story lines.

The first type as Figure 3:

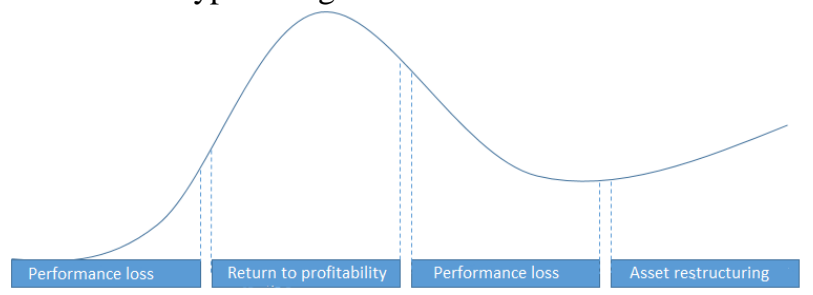

Figure 3. The first type of zombie enterprise evolution cycle

Because the main business of the enterprise is affected by the global macroeconomic and market downturn, its income continues to decline to a loss. Enterprises raise funds by issuing stocks, adjusting the depreciation period of fixed assets, selling fixed assets of enterprises, and transferring the shares held by them. In addition, the government provides financial support to enterprises, so as to achieve a return to profitability in a short time. However, because the conditions of the industry are not improving, the business is still in a state of difficulty. At this time, in order to get rid of the loss situation completely, the enterprise began to carry out an, which ushered in new profit business for the enterprise, or carried out its own adjustment and upgrading, and searched for new innovative profit points without changing its main business.

The second type, as Figure 4:

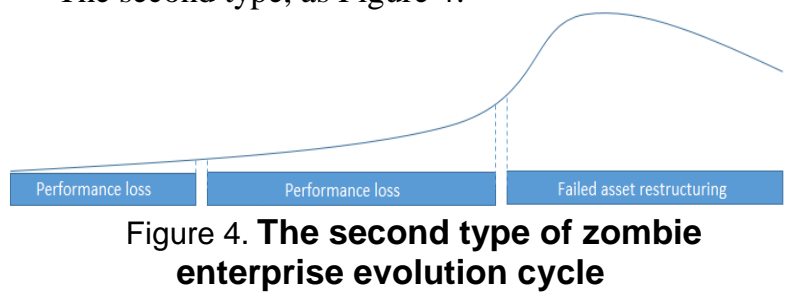

Under the influence of international macro market, some enterprises have suffered from performance loss. Enterprises have also taken measures to raise funds, but the proceeds from the operation do not make up the company's huge losses, so that the company is still in the performance losses. Facing to such situation, enterprises can only find a way to abandon the main business that seriously hampers the development of enterprises and try to introduce new industries to make profits for enterprises. However, due to the wrong control of the industry market, the newly introduced industries are not good industries or cannot bring huge profits to enterprises, so enterprises cannot get rid of the predicament of performance loss as expected.

The third type, as Figure 5: 


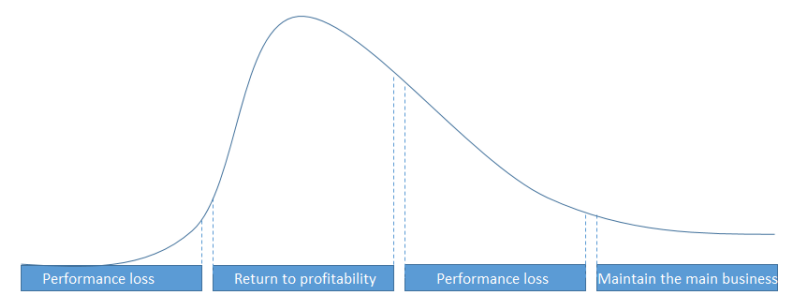

Figure 5. The third type of zombie enterprise evolution cycle

Under the influence of international macro market, some enterprises have suffered from performance loss. Enterprises took various measures to raise funds, so as to achieve profitability in a short time. However, the overall situation of the industry has not been improved, and the main business of the enterprise is still in an untenable state. Therefore, after the temporary impact of non-operating income is over, the enterprise still presents a situation of performance loss. However, in this case, the enterprise adhering to its main business, who doesn't attempted to change the scope of business, only places its hope on government's and market's better running in order to make the performance of the business profitable.

The fourth type, as Figure 6:

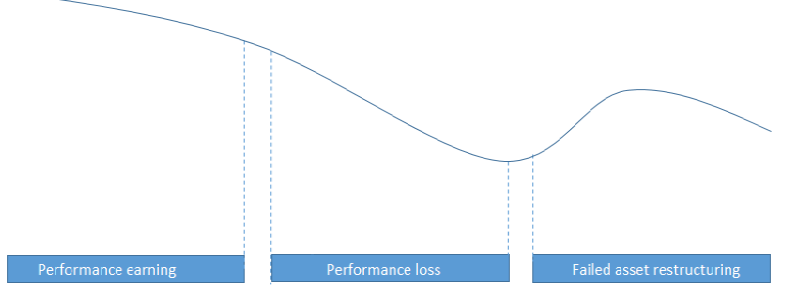

Figure 6 . The fourth type of zombie enterprise evolution cycle

At the initial stage, the company is in a state of profitability due to adequate supply of raw materials, strong market demand and rising product prices. However, as the international economic situation turns into a downturn, enterprise performance gradually turns from profit to loss. Enterprises try to change the situation of continuous loss through asset reorganization, but they are still in the predicament of performance loss due to the problems of the asset enterprises to be placed in.

The fifth category as Figure 7:

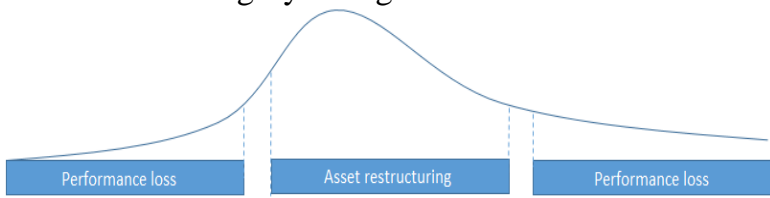

Figure 7. The fifth type of zombie enterprise evolution cycle

Under the influence of international macro market, some enterprises have suffered from performance loss. Facing to the situation, enterprises choose to cut down those troublesome businesses and introduce in new assets, resurging the enterprises. But because they don't fully understand the market and the industry, the new asset was in a difficult position. Enterprises fail to get rid of performance loss with the transformation of the business as expected. On the contrary, they continue to be trapped in a new cycle of performance losses.

\subsection{Analysis of cause-effect diagram}

Professor Jay w. Forrester of M.I.T. has created a system dynamics model, which is a quantitative method based on systems theory and feedback control theory, using digital simulation techniques to analyze sophisticated social economic systems[10]. In this way, we can fully understand the connection among variables in the system and the relationship between the system and the external environment, analyzing the process and key factors of the development and evolution of zombie companies.

The "+" and "-" arrow, which is the correlation between the two variables in the causation diagram, represent the positive and negative causality of the variables. According to the causal relationship among various variables in the system, the final causal closedloop circuit is constructed successively [11].

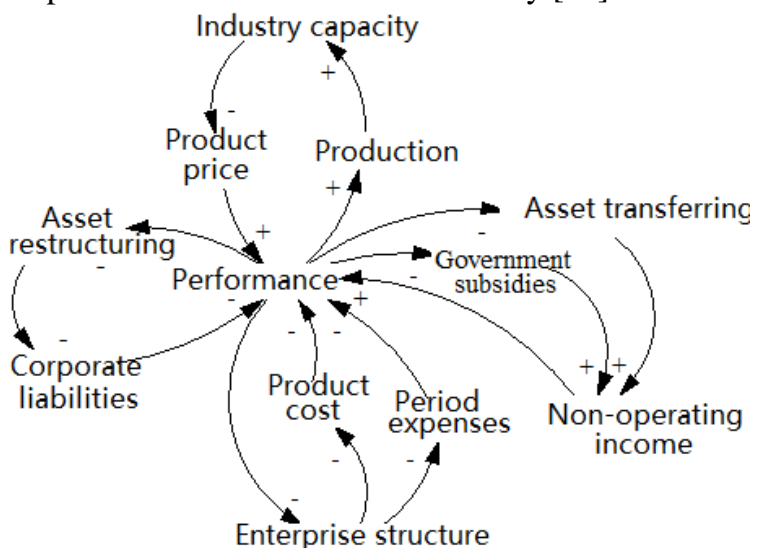

Figure 8. Causal feedback loops I

The four causal feedback loops in Figure 8 cover the four stages of the first type of zombie enterprise evolution cycle. In the first stage, the performance of zombie companies is in the stage of severe loss, as the industry's overcapacity reduces product prices and corporate performance. In the second stage, the zombie companies take measures to make his own performance to achieve the profit in a short time, such as adjusting their production model and depreciation standards, as well as selling their own inherent equity, industry and other assets. At the same time, the subsidies and support provided by the government to enterprises temporarily increased their non-operating income and turned the performance of enterprises 
around in a short time. In the third stage, the enterprise is affected by the macro-environment, and the final performance of the enterprise will return to the loss state. In the fourth stage, when the performance of the enterprise is extremely loss-making, the enterprise considers asset restructuring by selling its unprofitable assets and liabilities, and then putting in the good assets of other companies. As a result, the enterprise will reduce its liabilities, so as to make up for its losses and improve its performance.

The evolution model of the second type of zombie enterprises can also be explained by the four causal feedback loops in Figure 8. While in the second stage, there is a problem in the feedback loop. The enterprise accepts the government's financial subsidy and takes actions to increase revenue and reduce expenditure. However, the profit quota still cannot meet the original fund gap of the enterprise, and the enterprise is still in the state of performance loss. The company began to restructure itself. However, when carrying out asset replacement and reorganization, the enterprise did not effectively inspect and measure the newly introduced enterprise assets, which cannot make the newly introduced assets become good. Finally, the enterprise fails to reverse losses through restructuring.

The development and evolution model of the third type of zombies are also applicable to the four causal feedback loops in Figure 8. However, in the first stage, the strong demand in the early stage of the enterprise drives the growth of downstream demand, which makes the enterprise in the state of performance profit. However, as the market tends to be weak, the company's performance suffers from losses. In the process of the second stage, the enterprise failed to reverse performance loss. In the process of the third stage, the enterprise in the assets reorganization, has failed to study all the details of asset, which makes the enterprise fail to complete asset restructuring as expected. Enterprise was forced to keep the original operating mode, so the final business performance is still losing.

The evolution model of the fourth category of zombies is also applied to the four causal feedback loops in Figure 8. Enterprises just directly select asset restructuring in the second stage, which is not taking some measures of fund remedies like the other kind of evolution model. However, when the enterprise is going to do asset replacement restructuring, it doesn't have an effective survey and measure of the new business assets. In this case, it's not going to be able to reassemble the new asset in a short time, and it can only start to make some adjustments to its own operations, and accept some of the money from the government's bailouts, Striving to maintain the survival of the enterprise, but which did not make up for the gap of original performance loss, so that the enterprise still in the performance loss.

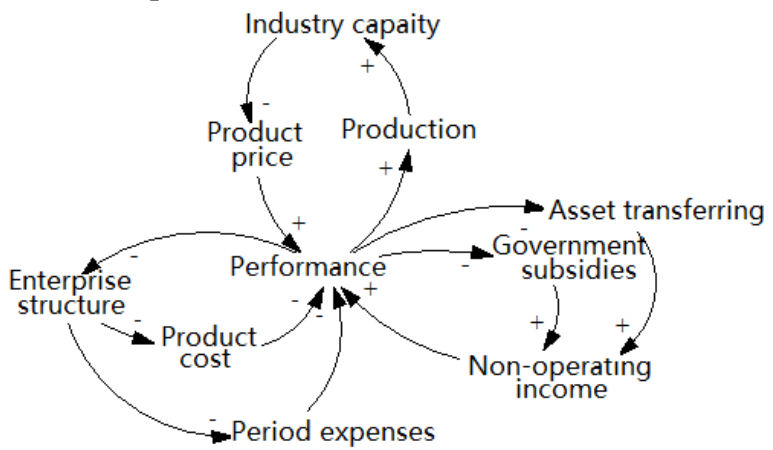

Figure 9. Causal feedback loops II

However, for the cycle diagram of the evolution model of zombies shown in Figure 5, there are only three feedback loops, rather than the causal four, as shown in Figure 9. In the early stage of development and evolution, such zombie companies are similar to the evolution model in Figure 3. But in the final stage, companies were found that they still stick to the original industry business areas in the situation that they cannot save themselves. And they do not find new good assets to make any improvement to the enterprise's operating production.

\section{Conclusion}

According to the theoretical framework obtained in this paper, some obvious characteristics of zombie companies have been embodied in the stage of development and evolution. The reason of zombie companies is the poor demand of the market. The critical reason why they can still survive relies on financial subsidy from government and assets. Continuous loss of enterprise performance is a visual manifestation of zombie companies. Taking immediate remedial measures according to these characteristics can prevent an enterprise from further deteriorating.

From the perspective of government, if any item goes as the following situation, the government should pay more attention and help the enterprises reduce the cost and expense, so as to help them solve the loss by more effective management and technology from the root: 1. Performance loss gradually, and the business situation is very bad, bank loans and other company loans overdue, conceal oneself circumstance and criticized by the CSRC, top executives have resigned, and so on. 2. Companies are unable to control the macro impact and take some self-help measures to try to reverse their income, including selling off other companies' equity stakes, selling fixed assets, raising funds frequently, applying for loans from the parent company, and receiving subsidies from the government. 
In addition, the government should also help enterprises reintroduce better assets, revitalize enterprises in the new sunrise industries and improve their performance.

From the perspective of the enterprise itself, according to the five different evolution types of enterprises, the following two measures can be chosen:

1. For enterprises that meet the description of the above type 1-4: When an enterprise finds that it cannot reverse the weak demand of the market industry in a short time, it can timely adjust the producing and operating conditions, thereby to reduce the expenses , and ensure that it can temporarily reverse the performance loss in the process of self-rescue. At the same time, it should consider changing its main business in time. Besides In the process of asset replacement, the author suggest that new introduced assets are good and sound, and promote the development of enterprise performance, but also pay attention to the smooth completion of the asset replacement process between the company where the new introduced assets are located, so as to avoid any problems in the process of asset replacement. The replacement cannot be carried out, so as to ensure that zombie companies can get rid of performance loss more quickly. When an enterprise finds that it cannot reverse the weak demand of the market industry in a short time, it can timely adjust the producing and operating conditions, thereby to reduce the expenses, and ensure that it can temporarily reverse the performance loss in the process of self-rescue. At the same time, it should consider changing its main business in time. Besides In the process of asset replacement, the author suggest that new introduced assets are good and sound, and promote the development of enterprise performance, but also pay attention to the smooth completion of the asset replacement process between the company where the new introduced assets are located, so as to avoid any problems in the process of asset replacement. The replacement cannot be carried out, so as to ensure that zombie companies can get rid of performance loss more quickly.

2. For enterprises that meet the description of the above fifth type: when market demand is weak and cannot be reversed from loss to profits within a short time, they timely adjust their operation conditions, reducing their operating expenses, and ensure that enterprises can temporarily reverse their performance in the process of self-help. However, for the enterprise itself, this situation can only temporarily relieve the pressure on the performance loss of the enterprise. If we want to solve the problem of zombie enterprises fundamentally, we have to find a way to make a major business transition.

\section{Acknowledgments}

This work was supported by the National key research and development program (No.2017YFB0803300), National Natural Science Foundation of China under Grant 91546121 and 61702043, National Social Science Foundation of China under Grant 16ZDA055, and the Open Project Fund of Key Laboratory of Trustworthy Distributed Computing and Service (BUPT), Ministry of Education.

\section{References}

[1]Liu Kuifu, "Review of Foreign Studies on zombie enterprises", Foreign Economics \& Management, China, 2016, pp. 4-8.

[2] Fukuda and Nakamura, "Why Did Zombie Firms Recover in Japan", World Economy, BLANK, America, 2011, pp.1124-1137.

[3] Bruche and Llobet, "Preventing Zombie Lending". Review of Financial Studies, Britain, 2014, pp.923-956.

[4]Shen, C, "Credit rationing for bad companies in bad years: evidence from bank loan transaction data". International Journal of Finance \& Economics, 2002, 7(3):261-278.

[5] He fan, "To solve the problem of zombie enterprises, we first need to know how many zombie companies there are in China.", http://hb.qq.com/a/20160203/024222.htm, 2016.

[6]Giannetti M, Simonov A, "On the real effects of bank bailouts: Micro evidence from Japan". American Economic Journal: Macroeconomics, American, 2013, pp.135-167.

[7]Chernobai A, Yasuda Y, "Disclosures of material weaknesses by Japanese firms after the passage of the 2006 Financial Instruments and Exchange Law". Journal of Banking \& Finance, Elsevier, Holland, 2013, pp.1524-1542. [8]Kashyap A K, "Sorting out Japan's financial crisis" Economic Perspectives, American, 2002, pp.42-55

[9] Feng Mayao, Xie Yaoni, "Grounded theory: a new qualitative research method", Modern Education Theory, China, 2001, pp. 51-53.

[10]Forrester, J.W, Industry Dynamic, Cambridge: MIT press, Britain, 1961.

[11]Li Yanqi, "System dynamics analysis of information intermediaries participating in e-commerce system", Industrial Technology Economy, China, 2016, pp. 30-37. 